\section{GESTIÓN COMUNITARIA DEL RIESGO DE DESASTRE: UNA PROPUESTA METODOLÓGICA-REFLEXIVA DESDE LAS METODOLOGÍAS PARTICIPATIVAS}

José Sandoval-Díaz ${ }^{{ }^{*}}$ y Soledad Martínez-Labrín ${ }^{1}$

\section{RESUMEN}

Las metodologías participativas son cadavez másutilizadas entre investigadores/asy organizaciones vinculadas a la gestión comunitaria del riesgo de desastre. Bajo este contexto, el presente trabajo tuvo como objetivos i) analizar el componente epistemológico de la investigación-intervención socio comunitaria, y ii) explorar la aplicabilidad de una propuesta de ocho saltos metodológicos participativos a la gestión local del riesgo. A modo de conclusión, discutimos la importancia (auto) reflexiva y metodológica-procedimental de incorporar estrategias participativas en propuestas investigativas-interventivas socio comunitarias, como una contribución al agenciamiento y al mayor énfasis del conocimiento situado transdisciplinar, siendo un potencial vehículo movilizador de la reducción del riesgo de desastre a escala local.

\section{PALABRAS CLAVES}

Metodologías participativas, Reflexividad, Investigación en reducción de riesgo de desastre, Técnicas interventivas, Comunidad

\section{COMMUNITY DISASTER RISK MANAGEMENT: A METHODOLOGICAL-REFLEXIVE PROPOSAL FROM PARTICIPATORY METHODOLOGIES}

\section{ABSTRACT}

Participatory methodologies are increasingly used by researchers and organizations linked to community disaster risk management. Under this context, the present work aimed to i) analyze the epistemological component of the socio-community research-intervention, and ii) explore the applicability of a proposal of eight methodological participatory leaps to local risk management. As a conclusion, we discuss the (self)reflexive and methodological-procedural importance of incorporating participatory strategies in socio-community investigative-intervening proposals, as a contribution to agency processes and to the emphasis on transdisciplinary situated knowledge, being a potential mobilizing vehicle for risk reduction disaster on a local scale.

\section{KEYWORDS}

Participatory methodologies, Reflexivity, Disaster risk reduction research, Intervention techniques, Community

\author{
1. Departamento de Ciencias \\ Sociales \& Grupo de \\ Investigación en Género, \\ Ciudadanía y Territorio \\ (GECIT), Universidad del Bío \\ Bío, Chillán, Chile. \\ *Autor de correspondencia: \\ jsandoval@ubiobio.cl
}

Identificador: http://revistareder.com/ handle-0719-8477-2021-097

\section{RECIBIDO}

31 de enero de 2021

\section{ACEPTADO}

30 de abril de 2021

\section{PUBLICADO}

1 de julio de 2021

\section{Formato cita}

Recomendada (APA):

Sandoval-Díaz, J. \&

Martínez-Labrín, S. (2021).

Gestión comunitaria del

riesgo de desastre: Una propuesta metodológicareflexiva desde las metodologías participativas. Revista de Estudios Latinoamericanos sobre Reducción del Riesgo de Desastres REDER, 5(2), 759o. http://revistareder.com/ handle-0719-8477-2021-097

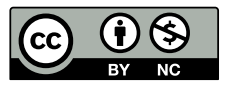

Todos los artículos publicados en REDER siguen una política de Acceso Abierto y se respaldan en una Licencia CreativeCommons Atribución-NoComercial 4.0 Internacional.

Revista de Estudios Latinoamericanos sobre Reducción del Riesgo de Desastres (REDER) 
"La palabra misma, investigación, es probablemente una de las palabras más sucias del vocabulario del mundo indígena".

Linda Tuhiwai (2016, p.13)

\section{INTRODUCCIÓN}

Los escenarios de riesgo de desastre se han convertido en uno de los principales obstáculos para la mantención y fortalecimiento en los logros de Desarrollo Humano globales y locales (UN Office for Disaster Risk Reduction [UNDRR], 2015). Ante estos extensivos e intensivos eventos, las estrategias transnacionales de reducción de riesgos de desastres (RRD) bajo la prioridad uno del Marco de acción de Sendai, han comenzado a reconocer la participación local como un elemento fundamental:

Velar porque se aprovechen como corresponda los conocimientos y las prácticas tradicionales, indígenas y locales, para complementar los conocimientos científicos en la evaluación del riesgo de desastres y en la elaboración y aplicación de políticas, estrategias, planes y programas para sectores específicos, con un enfoque intersectorial, que deberían adaptarse a las localidades y al contexto (UNDRR, 2015, p. 15).

Estos mandatos extraterritoriales han conllevado la reconfiguración multiescalar de las estrategias de gobernanza institucional de RRD, las cuales han desplazado su foco desde la perspectiva emergencista de corte verticalista, hacia el fortalecimiento multinivel de las capacidades de afrontamiento locales intersectoriales y, con marcado énfasis, desde las comunidades expuestas-susceptibles ante estos riesgos (Sandoval \& Sarmiento, 2018).

Bajo este giro paradigmático en los principios de la RRD, a nivel procedimental e institucional se torna necesario implementar estrategias de diagnóstico e intervención que releven las múltiples voces y prácticas sociales de los asentamientos humanos bajo riesgo socionatural, incluyendo no sólo los conocimientos formales (i) físico-materiales, (ii) socio-organizacionales y (iii) disposicionalmotivacionales relevados por expertos y/o gestores territoriales (Gaillard \& Mercer, 2013; Sandoval Díaz et al., 2018), sino también los saberes locales, prácticas consuetudinarias, racionalidades ambientales y ontologías relacionales propias de las comunidades territorializadas (Gaillard, Cadag \& Rampengan, 2019; Leff, 2019; Molina, Inostroza \& Constanzo, 2018; Tironi \& Molina, 2019).

De acuerdo con McNamara y Buggy, (2017), a principios del año 2000, a nivel institucional y académico emergen con fuerza modelos basados en la comunidad, reconociendo la importancia de i) la dimensión humana ante los cambios socionaturales, ii) la importancia del papel del conocimiento local para fortalecer capacidades, y iii) el relevo del ámbito local. A su vez, dentro de los distintos facilitadores de efectividad en gestión comunitaria del riesgo, se ha relevado la importancia de utilizar metodologías participativas para la implicancia activa en el diseño e implementación de programas locales (Cadag \& Gaillard, 2012; Mercer, Kelman, Lloyd \& SuchetPearson, 2008; Pelling, 2007).

En esta línea, y de acuerdo Marchezini et al. (2020) sostenemos la importancia de implementar modelos de primera línea en gestión local del riesgo. Esto, bajo la coproducción continua de mecanismos procedimentales de implicación y participación social transdisciplinarios. Es decir, que desborden las demarcaciones cientificistas de la racionalidad técnica experta, pero que no la excluyan de los procesos integrales de toma de decisiones complejas, como es el caso de la RRD. Un ejemplo de esto lo constituye el modelado participativo (MP) el cual vincula ciencia, tecnología, conocimiento y experiencias de las distintas partes interesadas, apoyando y permitiendo así la participación y toma de decisiones transversales en contextos de incertidumbre ambiental (Hubacek, Ravera, Tarrasón \& Prell, 2017).

Desde lo epistemológico, sostenemos la importancia de incorporar procesos sistemáticos de carácter flexible y situado en los que primen la participación y co-construcción continua de ecologías de saberes sobre el riesgo de desastre entre comunidad, ciencia y tomadores de decisiones (De Sousa Santos, 2013).

No obstante, previa planificación e implementación de estos modelos horizontales de gestión, debemos contar con cierta profundidad situada de y desde los conocimientos y vivencias 
territoriales, para lo cual es necesario disponer de una caja de herramientas pertinente y coherente con los objetivos de una RRD a escala local (Gaillard \& Mercer, 2013; Pelling, 2007; Tironi \& Molina, 2019). En esta línea, proponemos que la estrategia de Investigación Acción Participativa (IAP) favorecería la comprensión situada de los ensamblajes socionaturales a escala territorial, legitimando y posibilitando procesos de inteligibilidad intercultural epistémica (Meyer et al. 2018; Silva \& Bassi, 2016), sin caer, no obstante, en un romanticismo acrítico por el conocimiento local (Mercer et al. 2008).

Desde la IAP es imprescindible la ruptura onto-epistémica, ético-política y procedimental frente a las convencionales técnicas "ventriloquistas-extractivistas", esto con el fin de encontrar nuevas formas de comprensión ontológica basadas en la participación auténtica y transformación de las injusticias ambientales, espaciales y cognitivas que subyacen en los escenarios de riesgo de desastre (Grosfoguel, 2016; Villasante, 2011).

De acuerdo con esto, el objetivo del presente trabajo es doble: en primer lugar, i) analizar la dimensión epistemológica de toda investigación-intervención sujeto/a-sujeto/a, relevando las aportaciones conceptuales de las teorías feministas y de la ecología de saberes, para en segundo lugar, ii) explorar la aplicabilidad de metodologías participativas en RRD comunitaria y escala local. Para este segundo objetivo, aplicaremos el diseño de la Red de profesionales comprometidos con la transformación social y las democracias participativas (en adelante Red CIMAS), basado en ocho saltos: i) reflexión, ii) negociación, iii) mapas estratégicos, iv) escucha activa con multi-lemas, v) talleres de creatividad social, vi) planificación desde abajo, vii) estructura autoorganizativa y viii) evaluación y monitoreo del acompañamiento.

\section{DIMENSIÓN EPISTEMOLÓGICA DE LA INVESTIGACIÓN-INTERVENCIÓN}

La visión hegemónica que ha construido la investigación, desde el imaginario occidental, ha tendido a soslayar no sólo posiciones sociales dominadas históricamente, sino también formas de saber/conocer no categorizadas como científicas (Valiente, 2020). Los enfoques de investigación tradicionales, incluyendo muchos de corte crítico, se basan en una concepción de ser humano que tiene un afán generalizador, que anula las diferencias y reduce las contingencias a la invisibilidad (Mouffe, 1999) y al epistemicidio (De Sousa Santos, 2010). El resultado de ello son teorías y prácticas políticas que desconocen la relevancia de la interseccionalidad como eje analítico, mientras que, en lo epistemológico, estas metateorías universalizantes recurren al truco de separar el conocimiento del objeto y del sujeto, construyendo a un/a otro/a, como objeto exótico, problemático y sin capacidad de autoconstruirse (Haraway, 1995). Proponemos que el reconocimiento del diferencial por posicionalidad categorial sugerido por las epistemologías feministas y decoloniales, aborda las cuestiones epistemológicas con mucha profundidad y pluralidad.

Estas epistemologías proponen comenzar por el conocimiento de las vidas marginalizadas y problematizar la vida cotidiana, comenzando por la crítica a la objetividad tradicional, insuficientemente rigurosa y carente de capacidad objetivadora (Harding, 1993). Como consecuencia de una pobre operacionalización de lo 'objetivo' del método científico, estas perspectivas proponen que dicho abordaje no ha sido capaz de identificar su propio sesgo sexista, clasista y colonial, y aunque está histórica y localmente situado, simula ser universal:

Asunciones en toda la cultura que no han sido criticadas dentro de la investigación científica son transportadas a resultados de investigación, haciendo visible la historicidad de las pretensiones científicas específicas hacia personas en otros tiempos, otros lugares, otros grupos, dentro del mismo orden social (Harding, 1993, p.57).

Este conocimiento parcial, pero aparentemente universal, tiene como consecuencia la explotación y la legitimación de prácticas de dominación, ocultando que la posición o situación que alguien tiene en lo social, le permite y a la vez limita lo que puede conocer. Según esto, las vidas de las personas marginalizadas o vulneradas y su modo de comprensión pueden constituir problemas significativos (Valiente, 2020). Se propone así una epistemología del punto de vista, que es encarnado, visible e históricamente situado, teniendo presente la simetría causal, en la que las investigadoras/es son fundamentalmente similares al objeto de conocimiento, y proponiendo una reflexividad fuerte que permita hacer visible dicha simetría (Harding, 1993). El saber que emerge de allí es colectivo, en el sentido de que el conocimiento se vuelve relevante tan sólo 
cuando está socialmente legitimado y es múltiple y contradictorio, lo cual supone integrar diversos puntos de interseccionalidad (Harding, 1993). La reflexividad, de este modo, implica pensar críticamente en nuestro posicionamiento dentro de la investigación, como también transparentar dichos posicionamientos para ponerlos en un diálogo que desafíe las relaciones de poder que van configurándose a través de los procesos investigativos (Valiente, 2020).

También se ha planteado como fundamental concebir el conocimiento como históricamente contingente, de tal manera que logre una práctica crítica que dé cuenta del mundo real y que, al mismo tiempo, sirva a la vida (Haraway, 1995). Desde la crítica al universalismo androcéntrico de las epistemologías feministas, se reconoce que "necesitamos un circuito universal de conexiones, incluyendo la habilidad parcial de traducir los conocimientos entre comunidades muy diferentes y diferenciadas a través del poder" (Haraway, 1995, p. 322). Estos planteamientos ven a la persona como una confluencia de múltiples posiciones subjetivas, que son, a la vez, histórica y geográficamente situadas y que no se dan en el contexto de un sujeto/a estable e igual, sino en la relación de varios sujetos/as incoherentes y cambiantes (Haraway, 1995). El (re)nacimiento del sujeto/a en tanto que relacional (Burkitt, 1998) y articulado, pone a la relación como unidad de análisis, donde radicaría su capacidad transformadora y generadora de cambios.

En términos procedimentales, las metodologías participativas son también un intento por dar cuenta de procesos agénticos en la articulación investigativa. La agencia es aquí un concepto que no involucra la pérdida ni la ganancia absoluta de poderes de unos subordinados, sino la acción cotidiana, el quiebre del equilibrio cuyos efectos son impredecibles, pero que, sin embargo, tiene efectos y efectivamente subvierte el orden establecido (Butler, 1993). Lo anterior significa que no somos libres, pero tampoco completamente subordinadas/os, y que no toda agencia implica resistencia, pues la agencia puede resultar tanto en deconstrucción de discursos como en refuerzo de estos (Butler, 1993). El margen de subversión y rebeldía que el nuevo orden social nos deja como sujetas/os comunes es cada vez más difícil de entrever y nuestras acciones diarias parecen ser fagocitadas por una máquina enorme que nos produce (Haraway, 1999). Siguiendo a Foucault (1976), lo que torna una revolución posible es la "decodificación estratégica de los puntos de resistencia" ( $p .117)$ y no como podríamos pensar, las resistencias en sí. Esto nos lleva a pensar que las acciones diarias y aparentemente inofensivas, pueden ser leídas en código transformador; no una lectura que está esperando que las cosas cambien en una dirección predeterminada, ni que espera que la resistencia lleve a las personas a encontrar lo perdido, sino que una transformación situada, comprensiva de los procesos históricos, las situaciones y las multiples posiciones subjetivas. De este modo, la agencia está ligada con los procesos de transformación social, arraigados en la experiencia interseccional, entendiendo que la experiencia no tiene una calidad ontológica diferente de lo discursivo, sino que es discursiva "no son los individuos quienes tienen experiencias, sino que los sujetos son constituidos a través de la experiencia" (Scott, 1991, p. 26). Así, la agencia se relaciona con la posibilidad de actuar y cambiar, hasta ciertos márgenes, nuestro entorno social, en tanto que personas comunes, viviendo un cotidiano que es particular e inmerso en una serie de flujos complejos de poder y posibilidad que nos atraviesan. El sujeto político, entonces, no es secundario al hecho discursivo, sino que es eso mismo (Bhabha, 2002). Olvidar esto puede llevar a la sobretextualización de unas posiciones (a menudo subalternas) por parte de posiciones de sujeto de enunciación privilegiadas (a menudo hegemónicas) que no se textualizan, y con ello se naturalizan en el discurso, haciendo pensar que el sujeto por defecto pueda dar voz, entender 0 interpretar al sujeto cuya definición es necesaria.

Esto último llama la atención sobre la importancia de mantenernos alertas a la construcción, por inocente que resulte este acto, de la otredad en el acto investigativo, quitando el rol agéntico al sujeto investigado. En fecto, la separación sujeto-objeto en la objetividad tradicional funciona como un "truco divino" en el que el sujeto parece tener la facultad de mirar al objeto desde todos lados, por lo que le parece conocer más y mejor. La objetividad supone que quien investiga lo hace desde cuerpo no-marcado, que de este modo puede mirar sin ser visto, mientras que los objetos de la ciencia son cuerpos marcados bajo la "glotonería incontenible" (p. 325) de la vista del sujeto. El conocimiento tradicional espera que el objeto sea pasivo, que no sea agente, de tal manera que sea "un recurso" (Haraway, 1995). La naturaleza es, entonces, materia prima para la cultura.

Las metodologías que radicalizan la participación, rescatando la interseccionalidad y la agencia, permiten conservar al mismo tiempo heterogeneidad y comunidad (Burin 2002, Biglia 
\& Bonet-Martí 2009), al plasmar los relatos, sin apelar por fuerza a la lógica de jerarquización, ni de la presentación tradicional del conocimiento, el que además, como es habitual, consiste en invisibilizar las diferencias. Uno de los conceptos interesantes y de utilidad en este análisis será el concepto de diálogo. En Bahktin este concepto es incorporado para significar el hecho de que los sujetos son autores, pero que necesitan una relación para reclamar esa autoría, y que, por lo tanto, no son absolutos sino relativos a alguna otra parte con quien se dialoga (Burkitt, 1998). La unidad diálogo es pues relativa y cambiante y el sitio en donde la multiplicidad tiene lugar. Bakhtin (1990) incorpora el concepto de heteroglosia, para enfatizar que el diálogo es múltiple e intertextual. La heteroglosia es la expresión de las contradicciones, las diferencias y la posibilidad de generar nuevos lenguajes y nuevas formas de hablar (Bakhtin, 1990). Si asumimos eso, es coherente pensar que un discurso político crítico no produzca un objeto político nuevo, sino que abra un espacio de traducción dialógica.

La traducción aparece aquí como un concepto que promueve la multipicidad, en la que la superposición de significados no se produce, basado en la hermenéutica diatópica (De Sousa, 2009). La traducción cultural, en un sentido no moderno o multicultural, sino más deconstructivo (Buden, 2006) se entiende como un acto de creación sin origen esencial. En palabras de De Sousa (2009) un "procedimiento que permite crear inteligibilidad recíproca entre las experiencias del mundo, tanto las disponibles como las posibles... un procedimiento que no atribuye a ningún conjunto de experiencias ni el estatuto de totalidad exclusiva ni el estatuto de parte homogénea" (pp. 136-137). Esta traducción posibilitaría la hibridación como tercer espacio, ni del original, ni de quien traduce, por lo que tendría un carácter contraidentitario, en el cual las divisiones y antagonismos binarios dejarían de funcionar (Buden, 2006). La traducción permite el cambio social transgresivo, en tanto permite rearticular la universalidad partir de lo que ha sido excluido, donde no hay una negación dialéctica de un lenguaje u otro, sino un puente que les une, un tercer espacio (Buden, 2009).

Sin embargo, no es posible la traducción como acto político contrahegemónico en el que quien traduce no reconoce las relaciones de poder establecidas entre saberes y prácticas (De Sousa, 2009) y lenguas (Spivak, 1993). Una visión multiculturalista ingénua de ello podría hacernos entrar en la construcción de zonas de contacto coloniales (De Sousa, 2009). Para que la traducción funcione como encuentro debería producir desplazamiento. De lo dicho se desprende la necesidad de leer las relaciones como unidades útiles para el cambio político. Relaciones en las que no se ve al otro como un ser transparente y en las que, por lo tanto, se necesita traducirlo constantemente, recurrir a "la capacidad común de lograr una comunicación eficaz sin recurrir a significados compartidos e interpretaciones predeterminadas" (Bauman, 1999, p.211). En dicha relación es precisamente la responsabilidad, al relevarnos de actuar como guardianes/as de lo correcto, lo que nos permite recibir y crear sorpresas e ironías del mundo y sus diferentes versiones (Haraway, 1995).

Es necesario comprender que todo proceso de traducción trasciende los aspectos meramente discursivos, rescatando también las prácticas materiales, poniendo el acento en las formas de hacer más que a los individuos y sus producciones. Sin embargo, estos haceres también están planteados en contextos relacionales, de tal modo que la persona que actúa la táctica no queda claramente separada de aquello que está vadeando (De Certeau, 1990). Así, la investigación pasa a ser un gerundio y una especie de conversación a la forma de un "flujo de agenciamientos vestigiales intersubjetivos que crea subjetividades en relación... de estarse siendo" (Haber, 2011, p. 24). Un acto de reconocimiento, de dejarse habitar por la conversación como táctica auténtica (Haber, 2011). La investigación participativa es, desde este punto de vista, una relación de aprendizaje indisciplinado, en la que conversar es un hacer versiones en relación con otras; "Ser-en-la-conversación”, convertirse en la relación con otro/a (Haber, 2011).

\section{PRINCIPIOS DE LAS METODOLOGÍAS PARTICIPATIVAS}

Para considerar verdaderamente la implicancia y horizontalidad metodológica en el proceso de gestión comunitaria del riesgo de desastre se plantea el diseño de ocho saltos basado el diseño de la red CIMAS (Caballero Ferrándiz, Martín Gutiérrez \& Villasante, 2019). Para esto, en primer lugar, partimos de dos principios fundamentales:

a. La investigación acción como paradigma transformacional: Con esto buscamos trascender las perspectivas que ubican a la IAP sólo como una técnica investigativa 
alternativa al binomio Cualitativo-Cuantitativo, sino más bien, como una caja de herramientas para el compromiso - pacto entre distintos tipos de experticias: a) los expertos/profesionales: quienes aportan con su experiencia y conocimiento en metodologías interventivas y de análisis informacional; b) los expertos/convivenciales: quienes son la base aportando con sus experiencias y vivencias; y por último $\mathrm{c}$ ) los expertos/dirigentes, quienes aportan su experiencia en distintos temas de interés para el proceso (Villasante, 2014). Por tanto, la IAP como paradigma influye sobre el resto de las técnicas investigativas-interventivas al horizontalizar la implicación de los propios sujetos de la investigación en su diseño, en tanto que la identificación de los problemas, (y sus respectivas soluciones), no quedan reducidas al sólo saber de los expertos profesionales del riesgo socionatural.

b. La participación como diseño socio-práxico: Desde las metodologías participativas, podemos identificar dos grandes fracasos: a) los elitistas y b) los basistas (Villasante, 2019). El elitismo académico/profesional si bien tiende a incorporar el criticismo denunciante ante las injusticias sociales, sigue reproduciendo tanto la verticalidad instrumentalizadora de los/las participantes, como él (des)agenciamiento de estos últimos. Por otro lado, encontramos los enfoques basistas los cuales, si bien relevan la importancia normativa de la transformación social, tienden a fracasar tanto por el excesivo voluntarismo activista basado en las buenas intenciones, pero con escasas garantías organizativas y metodológicas.

Por tanto, con el fin de superar el talante crítico (des)agenciador, como de la instrumentación técnica escasamente desarrollada, creemos que es necesario avanzar en un diseño de implicaciónacción socio-práxica, fundada en la complementariedad por deficiencia entre las estrategias de apertura a los sentidos-prácticas de la realidad estudiada (contexto de descubrimiento), con aquellas capaces de delimitar y concretizar la realidad (contexto de justificación) (Ibáñez, 2015).

De acuerdo con estos principios, describiremos y aplicaremos, de forma exploratoria y abierta a la discusión, los ocho saltos de la planificación de un proceso de diagnóstico-interventivocomunitario ante el riesgo de desastre, esto con el objetivo de a) resaltar el recorrido en fases para alcanzar niveles más profundos de consciencia de los riesgos y autoorganización para afrontarlos, b) resaltar la importancia metodológica no sólo de los saberes cualitativos que configuran la memoria histórica de las localidades, sino los componentes físicos materiales del peligro y su exposición y, por último c) enfatizar la indivisibilidad entre "acciones" metodológicas (cartografiar los riesgos) y sus productos (concientización de la vulnerabilidad) para la habilitación y desarrollo de capacidades (Cadag \& Gaillard, 2012; Pelling, 2007; Sandoval Díaz et al. 2018).

Paso 1: La autorreflexión de la comunidad expuesta y la emergencia del grupo motor Para Lavell (2003) la gestión local del riesgo comprende:

Un nivel territorial particular de intervención en que los parámetros específicos que lo definen se refieren a un proceso que es altamente participativo por parte de los actores sociales locales y apropiado por ellos, muchas veces en concertación y coordinación con actores externos de apoyo y técnicos (p.32).

No obstante, en muchas ocasiones los plazos determinados y acotados llevan a los gestores territoriales a instalar riesgos socionaturales (y sus correspondientes estrategias de afrontamiento) no percibidos ni aceptados por la propia comunidad expuesta-susceptible. Por tanto, previo al desarrollo del plan de gestión, es necesario la realización de dos pasos iniciales: a) En primer lugar, la constitución de un "grupo motor"1 mixto, e integrado por expertos/profesionales y expertos/ convivenciales, siendo central para estos últimos el interés por participar, implicarse y con disponibilidad de tiempo, con el objetivo de dar sostenibilidad al grupo (Villasante, 2014). Paralelo a esto, en segundo lugar, es necesario instalar b) instancias continuas de auto-reflexividad grupal, con el objetivo de sacar a la luz preconcepciones y juicios que pudiesen dificultar la horizontalidad decisional entre los actores (ej. soslayo o minimización de la memoria local por parte de los profesionales o desconfianza hacia los actores institucionales por parte de las comunidades). Para esto es necesario instalar dispositivos continuos de autorreflexión por medio de ejercicios de juegos de rol, líneas de tiempo, sociodramas o transectos territoriales (ver Figura 1), cuyo objetivo es la autolimitación de sesgos que dificulten el proceso.
1. Para Pichón-Riviere (1975), el grupo operativo se concibe como un conjunto restringido de personas que, ligadas por constantes de tiempo y espacio y articuladas por su mutua representación interna, se proponen, en forma explícita implícita, llevar a cabouna tarea, que constituye su finalidad, interactuando a través de complejos mecanismos de adjudicación y asunción de roles. 


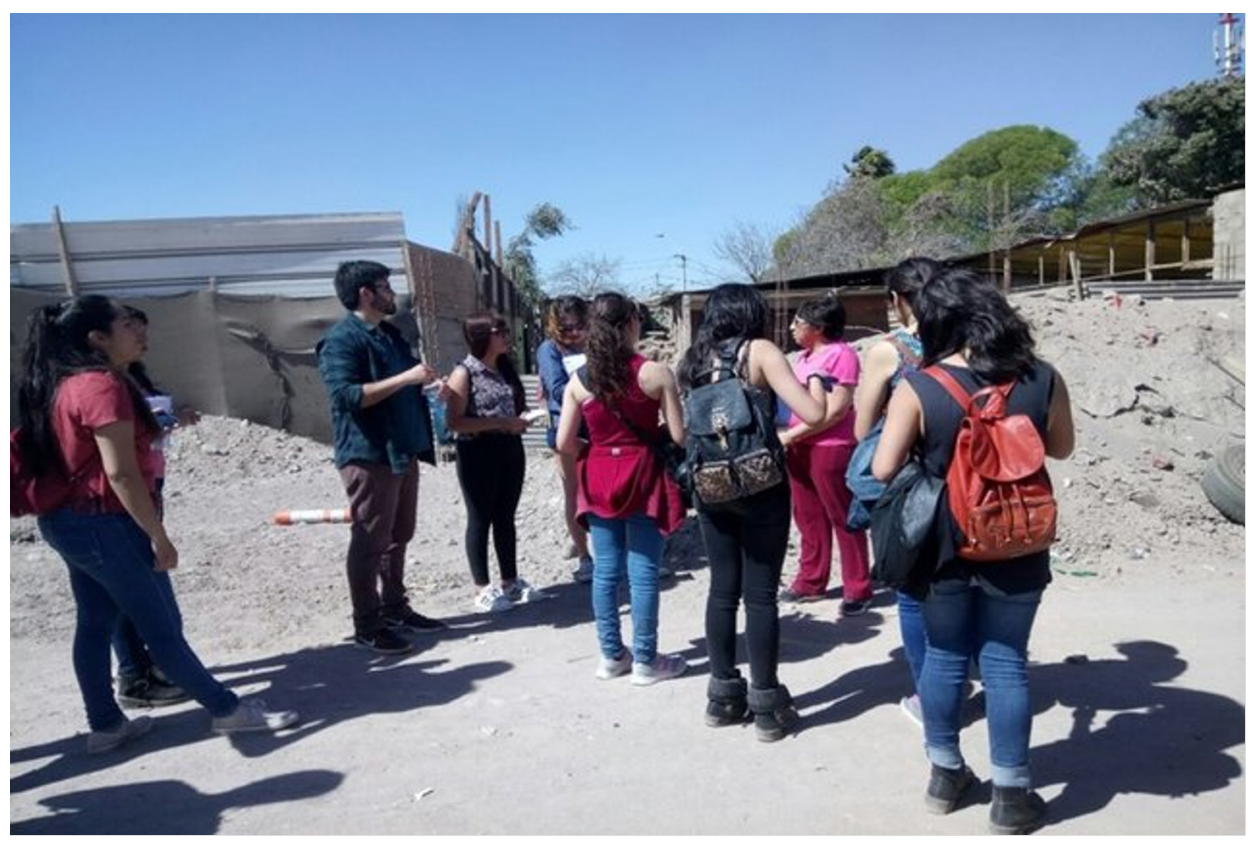

Figura 1. Aplicación de la técnica de transecto ante las inundaciones de Atacama, Chile

Fuente: Extraída de Sandoval-Díaz, Cuadra-Martínez, Orellana-Fonseca y Sandoval-Obando (2021)

\section{Paso 2: La negociación inicial y el plan de trabajo}

Develados los prejuicios cruzados entre los distintos actores pertenecientes al grupo motor, debiera comenzar la negociación inicial de i) objetivos, ii) metodología de trabajo, iii) tiempos, iv) recursos, y iv) formas de organización, evaluación y seguimiento del plan de trabajo. Estos encuentros iniciales y recurrentes entre los participantes del grupo motor, son necesarios no sólo para asentar la confianza e identidad basal entre los integrantes (al reconocer miedos, inseguridades y conocimiento ante el/los riesgo/s), sino también para identificar las distintas capacidades y alianzas integrupales que poseen como potencial equipo de trabajo, en términos de organización hacia la acción y potencial movilización de recursos ante las estructuras de oportunidades de tipo comunitarias, gubernamentales o mercantiles (Sandoval et al. 2018) - ver Figura 2.

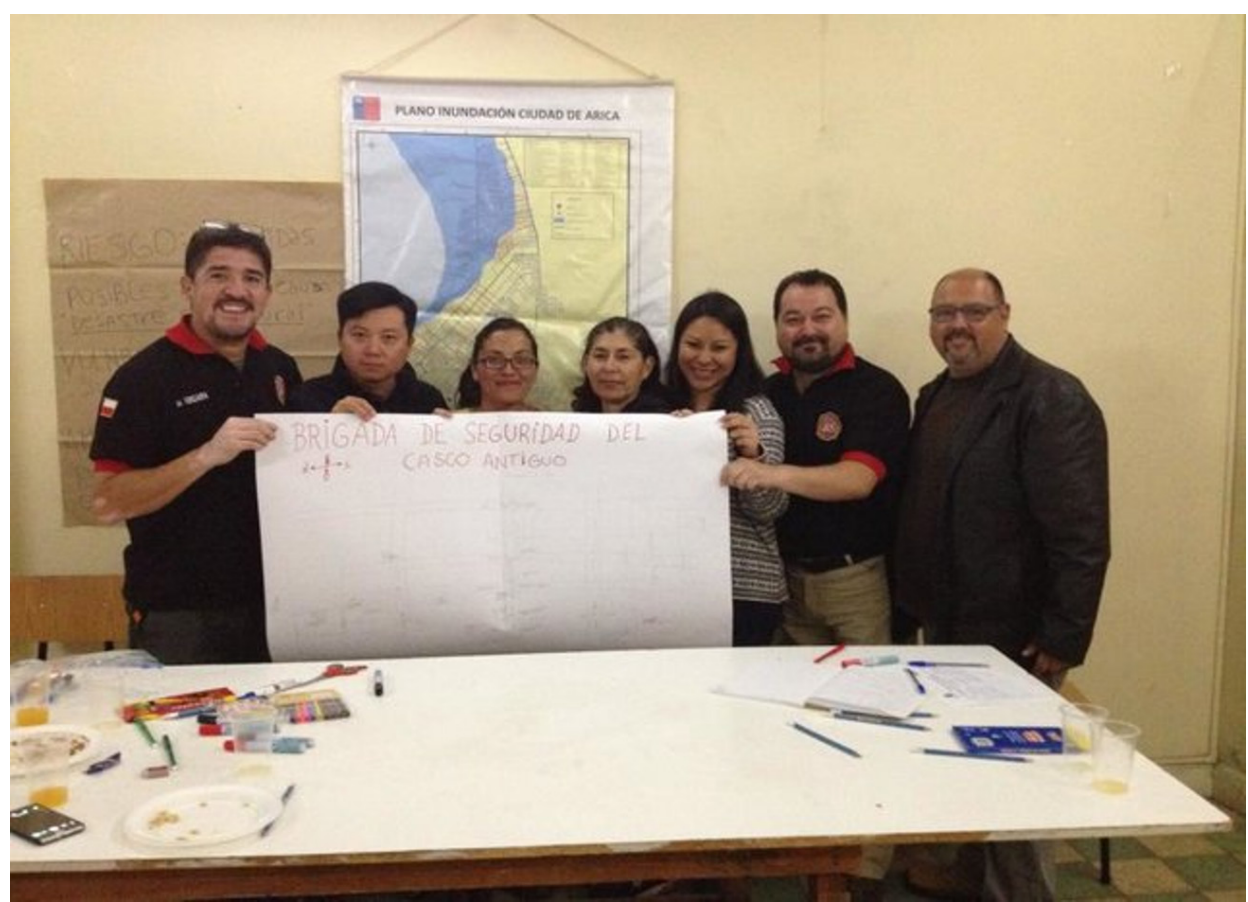

Figura 2. Grupo motor del casco antiguo de Arica, Chile

Fuente: Extraída de Sandoval-Díaz et al. (2018) 


\section{Paso 3: Mapas estratégicos y conjuntos de acción}

En esta etapa, el grupo motor elabora un mapeo estratégico de relaciones (sociograma o ecomapa ${ }^{2}$ ) entre los distintos actores sectoriales y territoriales de la gestión local del riesgo de desastre, valorando la diversidad de agentes involucrados (gubernamentales, comunitarios, privados, etc.), en términos de i) afines, ii) diferentes, iii) ajenos y iv) opuestos, esto con respecto a los objetivos iniciales del plan de trabajo elaborado (ver Figura 3).

En base a este mapeo inicial, se puede comenzar a establecer alianzas estratégicas intercomunidad y construir conjuntos de acciones, en términos de pequeñas redes sociales concretas de manejar que lo "político está en lo cotidiano", reconociendo, eso sí, la complejidad relacional al interior del entramado socioterritorial, en términos de i) redes de confianza y miedo al interior de las comunidades, ii) las condicionantes de clase social, género, raza e interseccionales, y iii) posiciones ideológicas ante la problemática en disputa (Caballero et al. 2019; Villasante, 2011).

Por otro lado, el componente comunicativo del plan de trabajo debiese paulatinamente adquirir fuerza más allá del grupo motor, es decir desbordándose hacia la comunidad no involucrada (ajena o opuesta) desde su misma cotidianidad territorial (Ej. reuniones de difusión, entrega de informativos, conversaciones cotidianas, actividades de ocio, etc.).

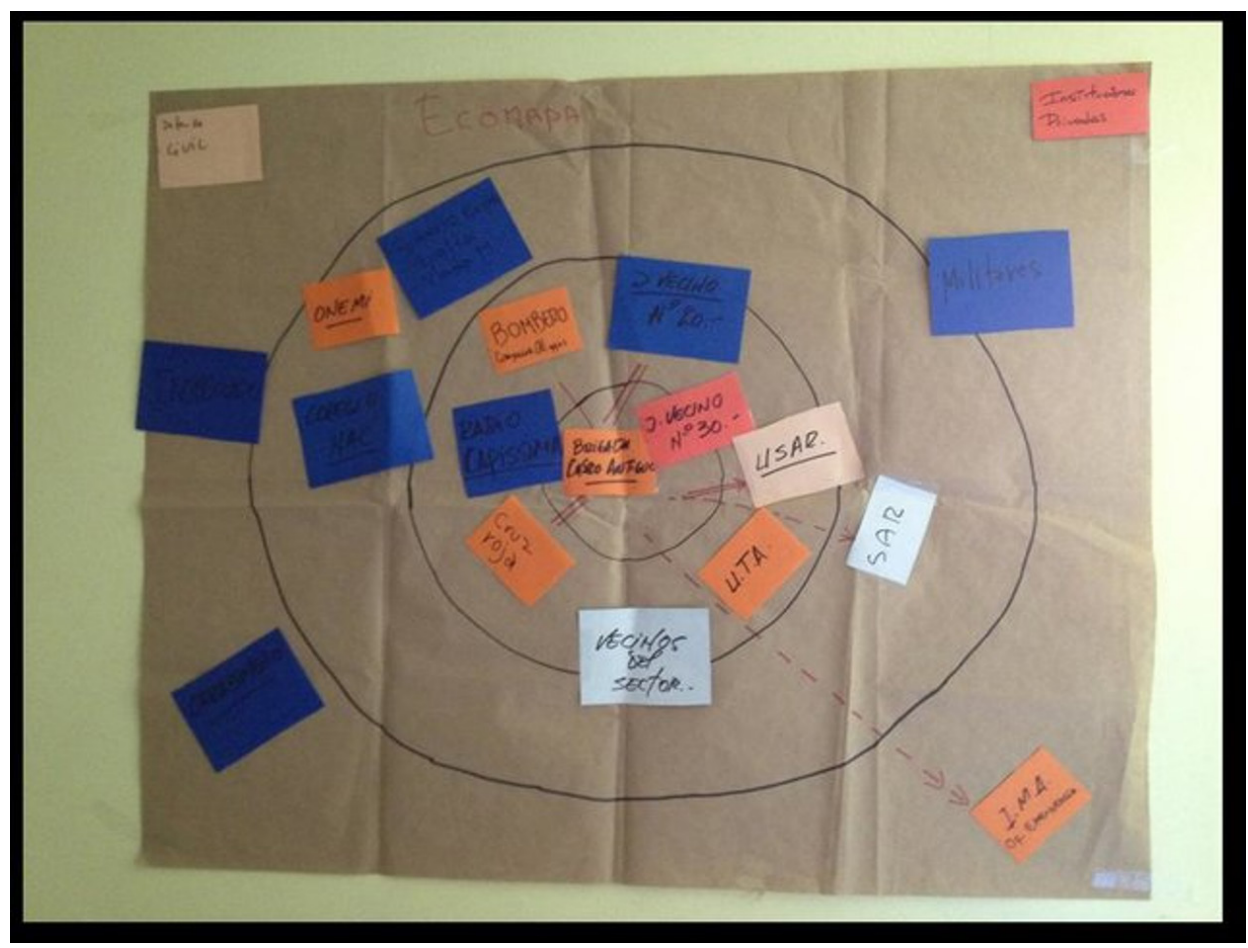

Figura 3. Ecomapa de la brigada Waña Qawa 1 de Arica, Chile Fuente: Extraído de Sandoval et al. 2018

\section{Paso 4: Escuchar más allá de los dilemas dominantes}

De acuerdo con Caballero et al. 2019, este tipo de escucha busca ir más allá del consenso de las mayorías, la interpretación academicista o de la mera saturación de información levantada, buscando no sólo hacer escuchar las "dinámicas socioculturales" de base, sino también, no dejando la escucha encerrada entre los grandes "dilemas mayoritarios" en desmedro de las opiniones minoritarias emergentes.

¿cuántas opiniones están enfrentadas en la comunidad o sector?, donde suele haber dos que se disputan la hegemonía entre lo dicho públicamente, y suele haber además otras dos o tres adicionales, que complejizan y profundizan el campo - lo que no se dicen a la primera, y que sólo en la confianza de un proceso aparecen - (p. 32).

En términos de herramientas capaces de desbloquear dilemas bipolares y antagónicos para rescatar y dar protagonismo a discursos emergentes, encontramos los tetralemas ${ }^{3}$. De acuerdo con González-Rodríguez (2006) los tetralemas (ver Figura 4) son matrices dialécticas que
2. El ecomapa es una técnica ecológica que grafica las relaciones de cercanía, distancia o ausencia entre comunidad e instituciones públicas/privadas a lo largo del ciclo del desastre.

3. La lógica aristotélica sólo cabe para los sistemas cerrados... para los sistemas abiertos en los que sólo hay identidad en el cambio, y hay cambios que reafirman la identidad, sólo vale una lógica dialéctica. La matriz de la lógica dialéctica es la lógica taoísta, su axioma fundamental es el tetralema (Villasante, 2006) 
recogen las distintas posturas ante una cuestión determinada, evitando la reducción de discursos cristalizados contrapuestos (ej. de afirmación y oposición ante el plan). Esta herramienta "reflexiva de segundo orden", escasamente utilizada en la aplicación de metodologías participativas, nos ayudaría a superar "la lógica aristotélica de identidad, no contradicción y de tercero excluido, para hacer operar la contradicción" (p.307) en el marco de sistemas abiertos (altamente paradójicos, contradictorios y creativos), como lo es el caso de la vida cotidiana a escala local.

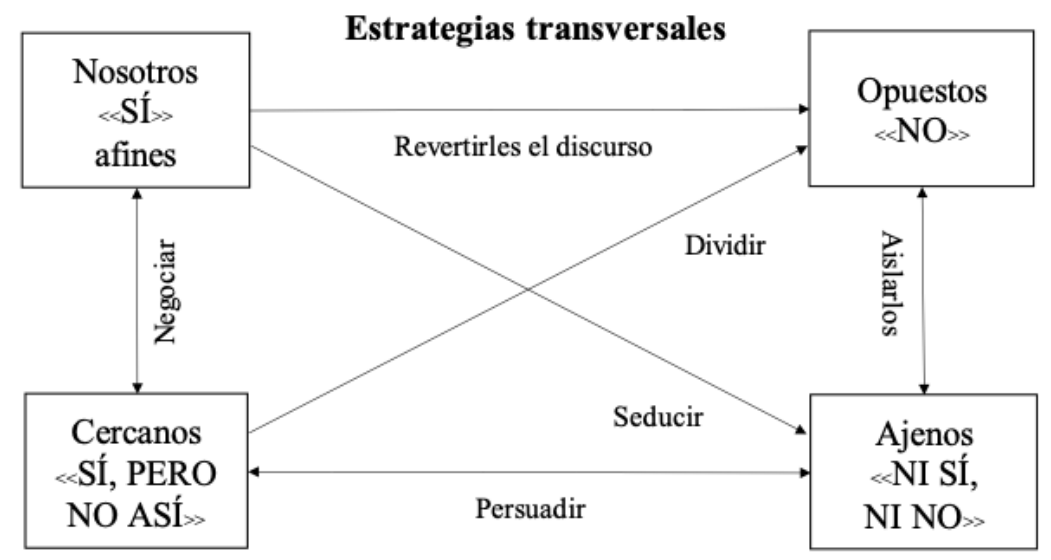

Figura 4. La estrategia de los tetralemas

Fuente: Extraído de González-Rodríguez (2006)

\section{Paso 5: Coproducir con talleres de creatividad social}

Avanzadas las etapas anteriores, podemos comenzar la comunicación, retroalimentación y contrastación de la información levantada del plan con las distintas actorías involucradas. Esta "reflexividad en segundo grado" con y desde la comunidad, busca no sólo dar credibilidad al análisis realizado por el grupo motor, sino también profundizar, complementar o confrontar los "multilemas" previamente levantados.

En términos operativos, esta estrategia debe considerar distintos espacios y momentos según los objetivos mediatos/inmediatos planteados, en términos de talleres focalizados grupales (de carácter sectorial) o generales ampliados con toda la comunidad. De acuerdo con la Red CIMAS (2015), se pueden implementar diversos dispositivos de priorización participativa tales como "flujogramas" con las posiciones de los participantes y/o la confrontación con los distintos "multilemas" (mayoritarios y emergentes) recogidos previamente.

El flujograma es una técnica apropiada de devolución, la cual busca identificar relaciones de causa-efecto, ya sea partiendo de los "multilemas" seleccionados, o preguntando directamente a los participantes por los elementos centrales a considerar en el plan de trabajo. Además de posibilitar la priorización de tres o cuatro temas por donde se puede empezar a trabajar, también es posible identificar los actores responsables del desarrollo e implementación de soluciones a las mismos (Ver figura 5).

Como producto final de estos talleres debiéramos obtener un autodiagnóstico colectivo, considerando para esto:

1. Que la comunidad sienta que su opinión vale en términos consultivos y decisionales (componente ético de la escucha).

2. Que se identifiquen y reconozcan las opiniones mayoritarias y las minoritarias emergentes.

3. En grupos pequeños (para democratizar la palabra), profundizar en las causas manifiestas y ocultas sobre la problemática de riesgo de desastre.

4. Integrar, evaluar y validar las tácticas/estrategias de solución propuestas por el grupo motor, con respecto a aquellas emergentes. 
5. Diferenciar y priorizar qué propuestas son más urgentes ${ }^{4}$, cuáles son temáticas de fondo (muchas veces de orden socio estructural) y cuál será la idea-fuerza que movilizará el proceso de gestión comunitaria.

6. 6. Por último, se proponen grupos mixtos (territoriales y sectoriales) focalizados en la implementación de propuesta consolidadas tanto de carácter urgente (ej. creación de comité de emergencia) como mediatas (ej. desarrollo plan de gestión del riesgo local).

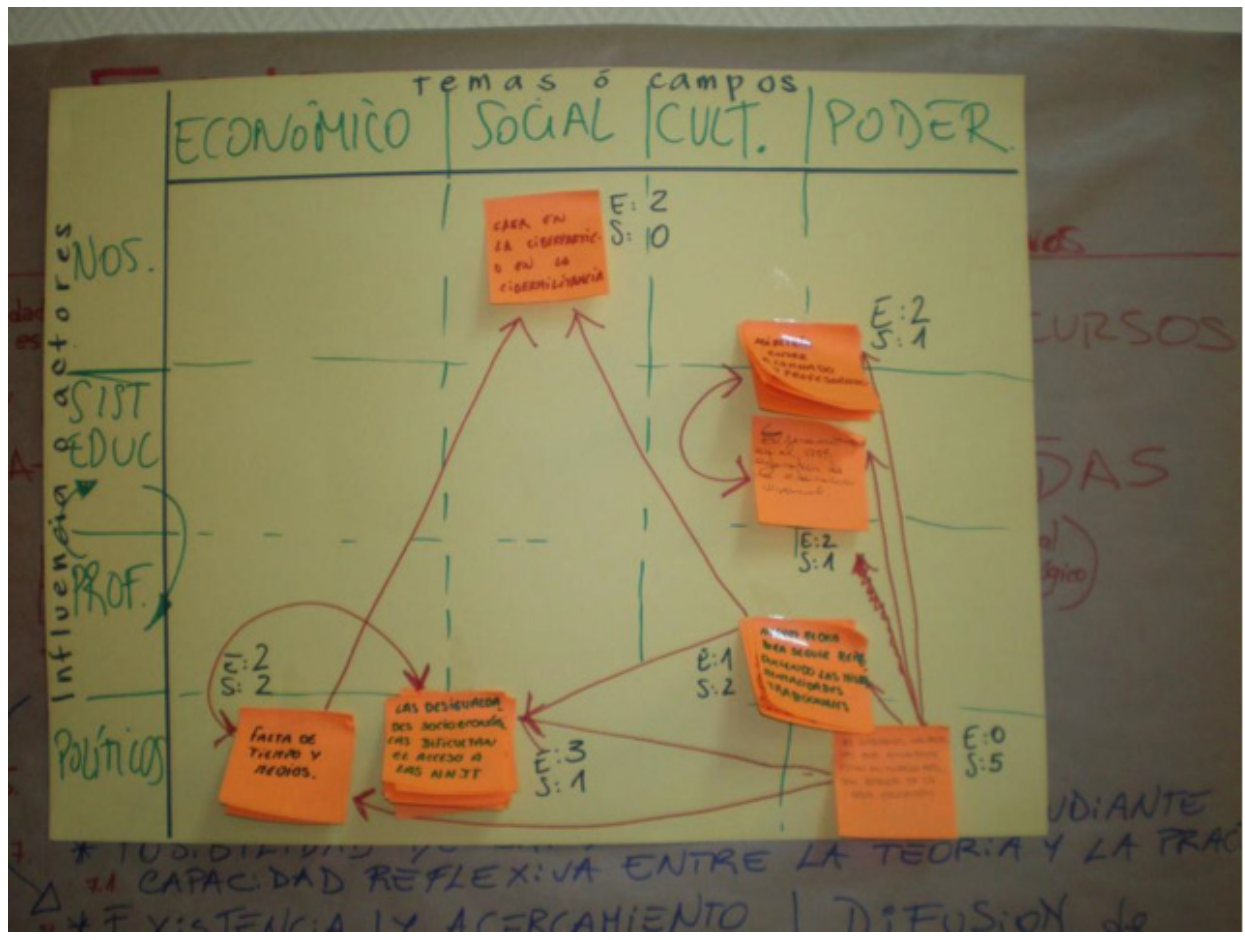

Figura 5. Ejemplo de flujograma en matriz Fuente: Extraído de CIMAS (2009)

\section{Paso 6: Planificación de urgencia y a mediano plazo}

Diferenciadas las propuestas entre a) urgentes, b) estructurales y de c) Idea-Fuerza, es necesario dar el salto hacia la implicancia y compromiso ante las distintas tareas constitutivas del plan de trabajo, considerando para esto la i) integralidad de las temáticas abordadas, ii) la sostenibilidad que esta tenga en el tiempo y iii) las prioridades de acción que sostienen al "sujeto/a colectivo/a" (construido en el hacer mismo de las prácticas).

En términos procedimentales, un elemento importante es la descentralización de responsabilidades del grupo motor inicial (el cual podría actuar ahora como grupo de seguimiento de las distintas propuestas priorizadas), recayendo ahora mayores responsabilidades entre los distintos grupos emergentes mixtos. Un elemento importante, en términos de legitimidad de estos grupos de trabajo, es la diversidad etaria, de género, afinidad cultural, religiosa e ideológica entre sus integrantes constitutivos, en pos de abrir e incorporar posiciones discursivas variadas de aquellos diferentes y ajenos inicialmente al plan de trabajo (Caballero et al. 2019). Por tanto, se trata de superar los personalismos y conflictos intergrupales, desbloqueando los nudos críticos por medio de la participación y la creatividad colectiva de la comunidad (ver Figura 6).

\section{Paso 7: La capacidad autoorganizativa de la comunidad}

Un elemento central para la sustentabilidad de la propuesta recae en el grado de autoorganización que posea la comunidad, lo que nos lleva más allá de los tiempos y responsabilidades puntuales de la propuesta del plan de RRD planteado. Por tanto, a nivel interno no sólo se debe ampliar e incorporar la diversidad de quienes residen en la comunidad, sino también, a nivel externo debiese equilibrar procesos de autogestión con cogestión de los gobiernos locales donde habitan las comunidades, en términos de redes democráticas-participativas.

Si bien esta construcción de experiencias de democracias participativas es ante todo un estado deseable (y sobre todo justo), en lo práctico, de acuerdo con las características estructurales
4. Las propuestas urgentes, son necesarias para la implicación y compromiso de la comunidad con el proceso, esto de acuerdo con lo planteado por Villasante (2017) "para que no vuelva la frustración es preciso que la gente vea y compruebe que sus iniciativas desde la vida cotidiana pueden encontrar un cauce y llegar a realizarse" (p. 180). 
e institucionales neoliberales de Chile, esta estructura de gobernanza participativa cogestionada es pobremente implementable y viable en nuestra realidad, conllevando sólo la ampliación e intensificación de las causas profundas de la vulnerabilidad subyacente (Sandoval et al. 2020; Sandoval \& Voss, 2016).

Por tanto, planteamos colaborar desde abajo (no sólo coordinando desde arriba), integrando al proceso todas las capacidades de las actorías vinculadas al territorio, en términos de sinergia de iniciativas emergentes de y desde lo cotidiano. Una "democracia de iniciativas" donde los protagonismos son compartidos, pero no reducidos al resilientismo autogestionado del "pueden adaptarse/salir adelante solos" (Sandoval-Díaz, 2020).

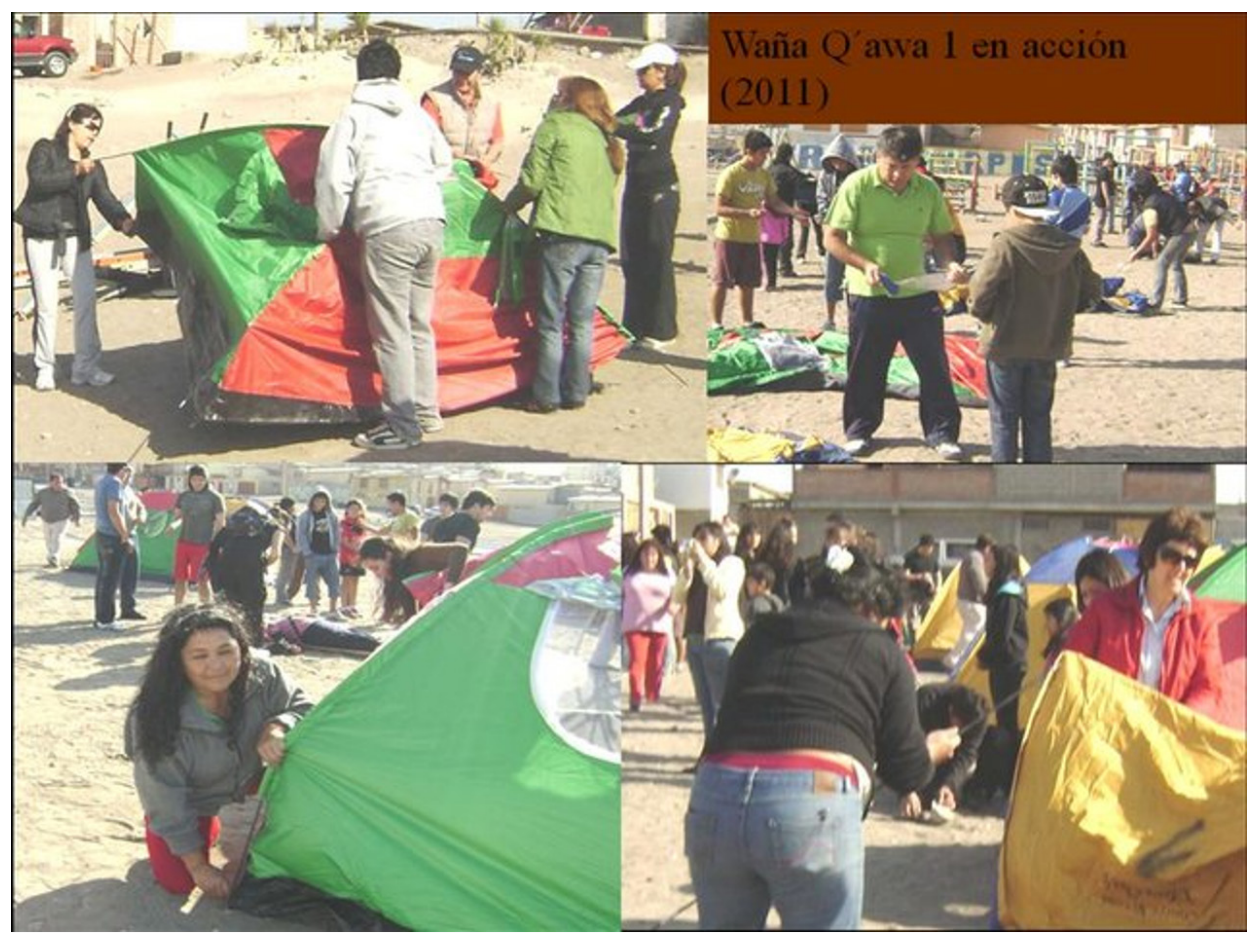

Figura 6. Talleres comunitarios de uso de equipamiento de emergencia en Arica, Chile Fuente: Extraído de Sandoval et al. 2018

\section{Paso 8: Los enfoques transductivos y los desbordes necesarios}

Para Villasante (2011) lo transductivo:

Son conceptos que se usan en ciencias naturales y sociales con un sentido parecido, es decir, acostumbrarse a transformarse dando saltos de un tipo de energía a otra. Por ejemplo, pasar de la energía calorífica a la electricidad, o de una acción hormonal en una enzimática en las proteínas. Son transformaciones que ocurren continuamente en nuestras vidas y entorno, aunque no seamos muy consciente de ello. Las transducciones se basan en unos dispositivos para crear "situaciones" peculiares de transformación, "provocaciones" con cierta transparencia, al estilo de las preguntas "mayéuticas" que formulaba Sócrates. De tal manera que el rigor crítico está en la forma y fondo de las preguntas, y se deja en libertad los caminos que se puedan o quieran emprender a partir de ellas (p.136).

Por tanto, lo transductivo busca desbordar los debates endogámicos, tanto academicista como activistas basistas, centrándose en transversalizar las propuestas en pos de resolver transformando la problemática concreta.

En segundo lugar, los procesos socionaturales (y societales) nunca acaban, emergiendo nuevos acontecimientos o efectos colaterales que desbordan los límites i) del plan de trabajo, ii) situacionales, iii) de la propia comunidad implicada, iv) como de los aprendizajes, tecnologías, conocimientos y metodologías utilizadas con anterioridad. Para esto es necesario instalar procesos de evaluación y monitoreo "auto-reflexivos" tanto a nivel interno (tanto de las éxitos y fracasos ético/metodológicos/prácticos del grupo motor con respecto al plan inicial), como externos (en 
términos de variabilidad y complejidad socionatural) apuntando a una "auto-eco-organización" sostenible ante las incertidumbres del tiempo-espacio cotidiano (Morin, 1994).

\section{DISCUSIÓN Y CONCLUSIONES}

A pesar del predominio de las estrategias tecnocráticas "de arriba hacia abajo", enfoques radicales han posibilitado un cambio de paradigma notable en RRD, instalando no sólo iniciativas para la planificación "de abajo hacia arriba", sino también, formas alternativas de investigación orientadas a la comprensión local y descubrimiento guiado por/desde la participación comunitaria ante el proceso de riesgo de desastre (Gaillard \& Mercer, 2013; Hubacek et al. 2017; McNamara \& Buggy, 2017, Mercer et al. 2008; Pelling, 2007).

El presente trabajo buscó analizar, desde una perspectiva exploratoria reflexiva, el papel que juega el componente investigativo en la gestión local del riesgo de desastre, tanto en términos epistemológicos como en términos procedimentales-operativos, esto bajo la lupa de las metodologías participativas. A modo de conclusión, presentamos un cuadro síntesis (ver tabla 1) de los saltos mencionados, identificando la importancia del para qué, el para quién, el porqué, el cómo y el qué, de las metodologías participativas, reconociendo i) su flexibilidad y adaptación ante las necesidades locales y, ii) énfasis en el compromiso con los participantes y el cambio social, por sobre lo técnico instrumental (Silva \& Bassi, 2016; Villasante, 2011; 2017; 2019).

La incorporación de metodologías participativas como facilitadoras del involucramiento y rol activo de las comunidades expuestas-susceptibles, en las últimas décadas se ha ido posicionando como un ethos procedimental común para la gestión local y la transdisciplinariedad en los estudios sobre el riesgo de desastre (Cadag \& Gaillard, 2012; Marchezini et al. 2020; UNDRR, 2015). No obstante, no basta que el encuentro entre experticias (convivenciales y profesionales) se reduzca a la mera traducción de lo ininteligible, sino más bien posibilitar la producción horizontal de un "tercer texto" bajo un contexto de igualdad discursiva y autonomía intertextual (Bakhtin, 1990; Buden, 2006; Corona Berkin, 2019).

La diferencia de este resultado con el hecho de hibridar, mestizar o combinar visiones, está en que la fusión anula la visibilidad de las diversas colaboraciones y la "mezcla" deja fuera precisamente el aporte de cada una. Por ello, recurrimos a otra metáfora, el tercer texto con miras a abandonar la perspectiva naturalista que insinúan las anteriores. Con tercer texto entendemos la producción que se realiza en diálogo, donde al hablar-dialogar con otros, necesariamente se modifican los lenguajes para llegar a comprender. La condición del tercer texto en este sentido es propia de lo nuevo, de los múltiples lenguajes humanos, cuya convivencia conflictiva generadora puede ser productora de nuevas respuestas a las preguntas sociales (Corona Berkin, 2019, p. 78).

Por otro lado, posteriores trabajos debieran seguir evaluado las potenciales ventajas documentadas de estas estrategias tanto a nivel investigativo, por ejemplo, en los modelos de adaptación basada en la comunidad (McNamara \& Buggy, 2017), formativo a nivel profesional (Sandoval-Díaz et al. 2021), intergeneracional vía modelamiento en 3D (Trejo-Rangel et al. 2021); Así como también a nivel institucional, tanto nacionales (metodología AIDEP ${ }^{5}$ del programa de microzonificación de riesgos y recursos de con participación comunitaria de la Oficina Nacional de Emergencia del Ministerio del Interior de Chile [ONEMI, 2017]), como internacionales (Naciones Unidas, Federación Internacional de la Cruz Roja y Sociedades de la Media Luna Roja, OXFAM).

A su vez, una tarea pendiente deriva no sólo en el cómo articular lo comunitario con la gestión institucional del riesgo, sino como extendemos el abordaje hacia problemáticas globales cada vez más complejas (tales como el cambio climático o la pandemia del COVID-19), esto con el objetivo de no caer en intervenciones aisladas, sino articuladas con los procesos de gobernanza multiescalares/multinivel para reducir la vulnerabilidad social (Sandoval et al. 2020; Sandoval \& Sarmiento, 2018; Sandoval \& Voss, 2016).

A modo de cierre, sostenemos que el relevo epistemológico-metodológico para el desarrollo de propuestas de RRD locales, debe ser acompañado de i) procesos institucionales de compromiso con los procesos de ciudadanía y cambio políico (Gaillard et al. 2019), ii) (Re)conocimiento de la ecología de saberes y toma de decisiones situadas sobre los riesgos percibidos/aceptados (De Sousa-Santos, 2009; 2010; 2013; Meyer et al., 2018) y iii) reducción estructural de las injusticias
5. Metodología de trabajo en que la comunidad examina el territorio que habita, reconociendo peligros, vulnerabilidades, recursos y riesgos. AIDEP, corresponde a un acróstico conformado por la primera letra de cada una de las etapas que comprenden esta metodología: a) análisis histórico, b) investigación en Terreno, c) discusión de prioridad de riesgos y recursos detectados, d) elaboración del mapa y e) planificación (ONEMI, 2017). 
espaciales, ambientales y cognitivas de los territorios en cuestión (Astudillo Pizarro \& Sandoval Díaz, 2019; Molina et al. 2018).

Por tanto, esta propuesta reconoce la complejidad dada por los procesos interseccionales que se dan en las comunidades y que suponen diferencias entre las diferentes actorías desde sus diversas experticias respecto de la situación dada (Haraway, 1995; Villasante, 2014). Efectivamente, cada territorio cuenta con una historia social y política que supone complejidades particulares que deben abordarse maximizando la reflexividad, a la vez que radicalizando la posibilidad de expresar la disidencia en lugar de homogeneizarla (Valiente, 2020). Finalmente, advertimos sobre la necesidad de utilizar la reflexividad como una herramienta útil para reconocer y promover la agencia de todas las actorías que participan del proceso investigativo, venciendo la tentación paternalista de dar voz o la ilusión de representar a quienes no participan de la experticia académica o científica.

\begin{tabular}{|c|c|c|c|c|c|c|}
\hline \multicolumn{7}{|c|}{$\begin{array}{l}\text { Planificación de Acciones Integrales Sustentables } \\
\text { (Saberes, en } 6 \text { Saltos - Tiempos, en los Procesos Socio-Praxicos) }\end{array}$} \\
\hline $\begin{array}{l}\text { Tiempos/ } \\
\text { Saberes }\end{array}$ & $\begin{array}{l}\text { Predisposición } \\
\text { desde las } \\
\text { experiencias } \\
\text { previas }\end{array}$ & $\begin{array}{l}\text { Construcción del } \\
\text { plan de trabajo } \\
\text { negociado } \\
\text { ( } 2 / 3 \text { meses) }\end{array}$ & $\begin{array}{l}\text { Trabajo de } \\
\text { campo y análisis } \\
\text { abiertos } \\
\text { ( } 2 / 3 \text { meses) }\end{array}$ & $\begin{array}{l}\text { Devoluciones } \\
\text { creativas y } \\
\text { priorizaciones } \\
\text { ( } 2 / 3 \text { meses) }\end{array}$ & $\begin{array}{l}\text { Propuestas } \\
\text { integrales y } \\
\text { sustentables } \\
\text { ( } 2 / 3 \text { meses) }\end{array}$ & $\begin{array}{l}\text { Proceso de } \\
\text { realizaciones y } \\
\text { seguimiento } \\
\text { con monitoreo }\end{array}$ \\
\hline $\begin{array}{l}\text { ¿Quién? } \\
\text { Saber estar }\end{array}$ & $\begin{array}{l}\text { Experiencias } \\
\text { sociales. } \\
\text { Capacidad de } \\
\text { autocrítica. }\end{array}$ & $\begin{array}{l}\text { (Eco)evaluar } \\
\text { prejuicios. } \\
\text { Conversar con } \\
\text { grupos. }\end{array}$ & $\begin{array}{l}\text { Escuchar todas } \\
\text { las posiciones. } \\
\text { Facilitar la } \\
\text { dinámica } \\
\text { de grupos. }\end{array}$ & $\begin{array}{l}\text { Dirigir talleres y } \\
\text { encuentros. } \\
\text { Provocar los } \\
\text { saltos creativos. }\end{array}$ & $\begin{array}{l}\text { Facilitar las } \\
\text { alianzas. } \\
\text { Planificar } \\
\text { participativamente. }\end{array}$ & $\begin{array}{l}\text { (Eco)dirigir } \\
\text { metodológicamente. } \\
\text { Monitorear } \\
\text { situaciones. }\end{array}$ \\
\hline $\begin{array}{l}\text { ¿Para qué? } \\
\text { Conocimientos } \\
\text { Episteme }\end{array}$ & $\begin{array}{l}\text { De las } \\
\text { vivencias con } \\
\text { analizadores a } \\
\text { la predisposición } \\
\text { para "Estilos } \\
\text { transductivos". }\end{array}$ & $\begin{array}{l}\text { De la buena } \\
\text { voluntad de } \\
\text { los sujeto/as- } \\
\text { sujeto/as a los } \\
\text { "Conjuntos de } \\
\text { acción." }\end{array}$ & $\begin{array}{l}\text { De los análisis de } \\
\text { acción-reflexión a } \\
\text { las paradojas y a } \\
\text { la reflexividad de } \\
\text { los Multilemas. }\end{array}$ & $\begin{array}{l}\text { De las } \\
\text { causalidades } \\
\text { "recursivas" a la } \\
\text { construcción de } \\
\text { nudos críticos } \\
\text { y "Ejes } \\
\text { Emergentes". }\end{array}$ & $\begin{array}{l}\text { De los indicadores } \\
\text { de sustentabilidad } \\
\text { a la Idea-fuerza. } \\
\text { Redes } \\
\text { democrático- } \\
\text { participativas. }\end{array}$ & $\begin{array}{l}\text { De los grupos } \\
\text { operativos a los } \\
\text { "Desbordes } \\
\text { creativos" } \\
\text { y procesos de } \\
\text { "Reversión". }\end{array}$ \\
\hline $\begin{array}{l}\text { ¿Por qué? } \\
\text { Metodologías }\end{array}$ & $\begin{array}{l}\text { Distinciones } \\
\text { entre } \\
\text { otras } \\
\text { metodologías y } \\
\text { lo participativo. }\end{array}$ & $\begin{array}{l}\text { Fases de un } \\
\text { proceso. } \\
\text { Problemática } \\
\text { inicial y análisis } \\
\text { de redes } \\
\text { Sociales. }\end{array}$ & $\begin{array}{l}\text { Complejidad de } \\
\text { conjuntos de } \\
\text { acción. } \\
\text { Temáticas } \\
\text { comunes y } \\
\text { contrapuestas. }\end{array}$ & $\begin{array}{l}\text { Planificación } \\
\text { estratégica } \\
\text { situacional. } \\
\text { Creatividad } \\
\text { con los grupos } \\
\text { heterogéneos. }\end{array}$ & $\begin{array}{l}\text { Idea-Fuerza y auto- } \\
\text { organización: } \\
\text { Democracia } \\
\text { Participativa y } \\
\text { Recursos. }\end{array}$ & $\begin{array}{l}\text { Articulación de } \\
\text { proyectos. } \\
\text { Evaluación y } \\
\text { monitoreo }\end{array}$ \\
\hline $\begin{array}{l}\text { ¿Cómo? } \\
\text { Saber hacer } \\
\text { Herramientas }\end{array}$ & $\begin{array}{l}\text { Trabajo en } \\
\text { grupos. } \\
\text { Salir a la calle. }\end{array}$ & $\begin{array}{l}\text { Sociodramas. } \\
\text { Transectos. } \\
\text { Sociogramas y } \\
\text { muestras DAFO. }\end{array}$ & $\begin{array}{l}\text { Entrevistas. } \\
\text { Talleres. } \\
\text { Análisis } \\
\text { Multi-lemas. }\end{array}$ & $\begin{array}{l}\text { Flojo-Gramas. } \\
\text { Talleres para } \\
\text { devoluciones } \\
\text { creativas. }\end{array}$ & $\begin{array}{l}\text { Votaciones } \\
\text { ponderadas } \\
\text { (EASW). } \\
\text { Esquemas de } \\
\text { Organización y } \\
\text { Recursos. }\end{array}$ & $\begin{array}{l}\text { Cronograma por } \\
\text { tareas y proyectos. } \\
\text { Campaña de } \\
\text { Difusión y (Eco) } \\
\text { Autoformación. }\end{array}$ \\
\hline $\begin{array}{l}\text { ¿Qué? } \\
\text { Resultados } \\
\text { operativos }\end{array}$ & $\begin{array}{l}\text { Formación } \\
\text { de grupos } \\
\text { implicados. }\end{array}$ & $\begin{array}{l}\text { Delimitación del } \\
\text { síntoma. } \\
\text { Grupo Motor y } \\
\text { muestra. } \\
\text { Plan de trabajo. }\end{array}$ & $\begin{array}{l}\text { Saturar las } \\
\text { posiciones de los } \\
\text { conjuntos de } \\
\text { acción. } \\
\text { Cuadros } \\
\text { temáticos } \\
\text { con Multi-lemas. }\end{array}$ & $\begin{array}{l}\text { Nudos críticos } \\
\text { priorizados. } \\
\text { Construcción } \\
\text { de la } \\
\text { red de } \\
\text { seguimiento. }\end{array}$ & $\begin{array}{l}\text { Informe Operativo: } \\
\text { propuestas, } \\
\text { organización y } \\
\text { recursos. }\end{array}$ & $\begin{array}{l}\text { Seguimiento } \\
\text { cronogramas. } \\
\text { Rearticulación de } \\
\text { Estrategias. }\end{array}$ \\
\hline
\end{tabular}

Tabla l. Cuadro síntesis aplicación de las metodologías participativas Fuente: Extraído de Villasante, 2011 (p. 143)

\section{FINANCIAMIENTO}

Trabajo financiado por la Agencia Nacional de Investigación y Desarrollo (ANID) en el marco de la ejecución del FONDECYT de Iniciación № 11200683 "Riesgos socionaturales intensificados por el cambio climático: análisis de la vulnerabilidad-resiliencia social a escala local" (2020 a 2022). 


\section{REFERENCIAS}

Astudillo Pizarro, F. \& Sandoval Díaz, J. (2019). Justicia espacial, desastres socionaturales y políticas del espacio: dinámicas sociopolíticas frente a los aluviones y procesos de recuperación en Copiapó, Chile. Cuadernos de Geografía: Revista Colombiana de Geografía, 28(2), 303-321. https://doi. org/10.15446/rcdg.v28n2.73520

Bakhtin, M. (1990). La cultura popular en la edad media y en el renacimiento: el contexto de Francois Rebelais. Madrid: Alianza Editorial.

Bhabha, H. (2002). El compromiso con la teoría. En H. Bhabha (Ed.), El Lugar de la Cultura (pp. 39-6o). Buenos Aires: Manantial.

Biglia, B. \& Bonet-Martí, J. (2009). La construcción de narrativas como método de investigación psicosocial. Prácticas de escritura compartida. Forum Qualitative Social Research, 10(1) 1-17. https:// www.psiucv.cl/wp-content/uploads/2014/o1/2666.pdf

Buden, B. (2006). Traducción cultural: por qué es importante y por dónde empezar. European Institute for Progressive Cultural Policies (EIPCP). Trad. Marcelo Expósito, revisada.

Burin, M. (2002). Otros deseos constitutivos de la subjetividad femenina. En M. Burin (Ed.), Estudios sobre la subjetividad femenina. Mujeres y salud mental (pp.131.185). Buenos Aires: Librería de Mujeres.

Burkitt, I. (1998) The death and rebirth of the Autor: the Bakhtin circle and Bordieu on individuality, language, and revolution. En Mayerfeld Bell, M. \& Gardiner, M. (eds.) Bakhtin and the Human Sciences (pp. 163-180). London: Sage.

Butler, J. (1993) Bodies that Matter. New York: Routledge.

Caballero Ferrándiz, J., Martín Gutiérrez, P., \& Villasante, T. R. (2019). Debatiendo las metodologías participativas: un proceso en ocho saltos. Empiria. Revista de metodología de ciencias sociales, (44), 21-45. http://revistas.uned.es/index.php/empiria/article/view/25350

Cadag, J. R. D., \& Gaillard, J. C. (2012). Integrating knowledge and actions in disaster risk reduction: the contribution of participatory mapping. Area, 44(1), 100-109. https://doi. org/10.1111/j.1475-4762.2011.01065.x

Corona Berkhin, S. (2019). Producción horizontal de conocimiento. Alemania: CALAS

De Certeau, M. (1990). La Invención de lo Cotidiano. Vol. I: Artes de Hacer. México: Universidad Iberoamericana.

De Sousa, B. (2009) Hacia una sociología de las ausencias y una sociología de las emergencias. En Una epistemología del sur: la reinvención del conocimiento y la emancipación (pp. 98-152). México: Siglo XXI-CLACSO.

De Sousa, B. (2010). Para descolonizar Occidente. Más allá del pensamiento abismal. Buenos Aires: CLACSO y Prometeo.

De Sousa Santos, B. (2013). Descolonizar el saber, reinventar el poder. Santiago: Lom Ediciones.

Foucault, M. (1976) Historia de la Sexualidad. Vol. I: la Volutad de Saber. Madrid: Siglo Veintiuno de España Editores, SA.

Gaillard, J., Cadag, J. \& Rampengan, M. (2019). People's capacities in facing hazards and disasters: an overview. Natural Hazards, 95(3), 863-876. https://doi.org/10.1007/s11069-018-3519-1

Gaillard, J. C., \& Mercer, J. (2013). From knowledge to action: Bridging gaps in disaster risk reduction. Progress in human geography, 37(1), 93-114. https://doi.org/10.1177/0309132512446717

González-Rodríguez, P. (2006). El uso del tetralema como una herramienta para abordar una segunda reflexicidad. La experiencia portada por la investigación participativa sobre la miniqueserías artesanales de Tenerife. Cuadernos de Trabajo Social, (19), 297-33o. https://revistas.ucm.es/index. php/CUTS/article/view/CUTSo6o6110297A

Haber, A. (2011). Nometodología Payanesa: Notas de metodología indisciplinada. Revista Chilena de Antropología, 23(1), 9-49. https://doi.org/10.5354/o719-1472.2011.15564

Haraway, D. (1995) Conocimientos situados. En Haraway, D. (Ed.), Ciencia, cyborgs y mujeres (pp. 313346). Valencia: Cátedra.

Harding, S. (1993) Rethinking Standpoint Epistemology: What is “Strong Objectivity”? En Alcoff, L. \& Potter, E. (Eds.), Feminist Epistemologies (pp. 49-8o). London: Routledge.

Hubacek, K., Ravera, F., Tarrasón, D., \& Prell, C. (2017). Participatory Modeling. International Encyclopedia of Geography: People, the Earth, Environment and Technology, 1-8. https://doi. org/10.1002/9781118786352.wbieg0293 
Ibañez, J. (2015). Perspectivas de la investigación social: el diseño en las tres perspectivas. En García Ferrando, M., Alvira, F., Alonso, L.E. \& Escobar, M. (Coord.), El análisis de la realidad social: métodos y técnicas de investigación (pp. 31-66). Madrid, Alianza Editorial.

Leff, E. (2019). Ecología política: De la deconstrucción del capital a la territorialización de la vida. Ciudad de México: Siglo XXI Editores

Grosfoguel, R. (2016). Del extractivismo económico al extractivismo epistémico y ontológico. Revista Internacional de Comunicación y Desarrollo RICD, 1(4), 33-45. https://doi.org/10.15304/ricd.1.4.3295

Morin. E. (1994). Introducción al pensamiento complejo. Barcelona: Gedisa

McNamara, K. E., \& Buggy, L. (2017). Community-based climate change adaptation: a review of academic literature. Local Environment, 22(4), 443-46o. https://doi.org/10.108o/13549839.2016.12169 54

Marchezini, V., Mourão, C., Scofield, G., Metodiev, D. \& Leite Flores, S.S. (2020). Sistemas Comunitários de Alerta de Risco de Desastres Associados a Inundações e Deslizamentos: Aspectos Teóricos e Metodológicos. Revista de Estudios Latinoamericanos sobre Reducción del Riesgo de Desastres REDER, 4(2), 36-56. http://www.revistareder.com/ojs/index.php/reder/article/view/49

Mercer, J., Kelman, I., Lloyd, K., \& Suchet-Pearson, S. (2008). Reflections on use of participatory research for disaster risk reduction. Area, 40(2), 172-183. https://doi. org/10.1111/j.1475-4762.2008.00797.x

Meyer, M.A., Hendricks, M., Newman, G.D., Masterson, J.H., Cooper, J.T., Sansom, G., Gharaibeh, N., Horney, J., Berke, P., van Zandt, S. \& Cousins, T. (2018). Participatory action research: tools for disaster resilience education. International Journal of Disaster Resilience in the Built Environment, 9(4/5), 402-419. https://doi.org/10.1108/IJDRBE-02-2017-0015

Molina, F., Inostroza \& Constanzo, J. (2018). Decolonizando los riesgos naturales: poder, territorio y conocimiento ancestral en la comuna de Saavedra, Chile. Journal of Latin American Geography, 17(1), 7-33. https://doi.org/10.1353/lag.2018.00o1

Mouffe, C. (1999) Feminismo, Ciudadanía y Política Democrática Radical. En Mouffe, C. (Ed.), El Retorno de lo Político (pp.107-126). Barcelona: Paidós.

Oficina Nacional de Emergencia del Ministerio del Interior. (2017). Microzonificación de riesgos y recursos con participación comunitaria: Elaboración de planes de emergencia comunitarios Metodología Acceder. Departamento de Programas: OMEMI. https://chile-preparado.onemi.gov. cl/wp-content/uploads/2017/12/Guia-comunidad-N\%C2\%Bo-2-Elaboraci\%C3\%B3n-Planes-deRespuesta-a-Emergencias.pdf

Red CIMAS (2015). Metodologías participativas. Sociopraxis para la creatividad social. Madrid, DEXTRA.

Red CIMAS (2009). Metodologías Participativas. Manual. Madrid: Observatorio Internacional de Ciudadanía y Medio Ambiente Sostenible.

Pelling, M. (2007). Learning from others: the scope and challenges for participatory disaster risk assessment. Disasters, 31(4), 373-385. https://doi.org/10.1111/j.1467-7717.2007.01014.X_

Pichón, R. (1975). El proceso grupal: Del psicoanálisis a la psicología social (I). Argentina: Ediciones Nueva Visión.

Sandoval, V., Gonzalez-Muzzio, C., Villalobos, C., Sarmiento, J.P. \& Hoberman, G. (2020). Assessing disaster capitalism in post-disaster processes in Chile: Neoliberal reforms and the role of the corporate class. Disaster Prevention and Management, 29(6), 831-847. https://doi.org/10.1108/ DPM-01-2020-0005

Sandoval, V., \& Voss, M. (2016). Disaster Governance and Vulnerability: The Case of Chile. Politics and Governance, 4(4), 107-116. http://dx.doi.org/10.17645/pag.v4i4.743

Sandoval, V., \& Sarmiento, J. (2018). Una mirada desde la gobernanza del riesgo y la resiliencia urbana en América Latina y el Caribe: Los asentamientos informales en la Nueva Agenda Urbana. Revista de Estudios Latinoamericanos sobre Reducción del Riesgo de Desastres REDER, 2(1), 38-52. http:// revistareder.com/handle-0719-8477-2018-011

Sandoval-Díaz, J. (2020). Vulnerabilidad-resiliencia ante el proceso de riesgo-desastre: Un análisis desde la ecología política. Polis (Santiago), 19(56), 214-239. https://dx.doi.org/10.32735/ so718-6568/2020-n56-1527 
Sandoval Díaz, J., Rojas, L., Villalobos, M., Sandoval, C., Moraga, F., \& Aguirre, N. (2018). De organización vecinal hacia la gestión local del riesgo: diagnóstico de vulnerabilidad y capacidad. Revista INVI, 33(92), 155-18o. http://dx.doi.org/10.4067/So718-83582018000100155

Sandoval-Díaz, J., Cuadra-Martínez, D., Orellana-Fonseca, C., \& Sandoval-Obando, E. (2021). Diagnóstico comunitario ante desastres climáticos: Una experiencia de aprendizaje-servicio. ALTERIDAD. Revista de Educación, 16(1), 23-37. https://doi.org/10.17163/alt.v16n1.2021.02

Scott, J. (1991). Experience. En Butler, J. \& Scott, J. (Eds.), Feminists Theorize the Political (pp- 22-40). London: Routledge.

Silva, J \& Bassi, J. (2016). Aportes teóricos y metodológicos para una investigación social situada. Antofagasta: Ediciones Universidad Católica del Norte.

Spivack, G. (1993). The politics of translation. En Spivack, G. (Ed.), Outside in the Teaching Machine (pp. 179-200) New York: Routledge.

Tironi, M. \& Molina, F. (2019). Desastres desde abajo el rol de los saberes locales en la gestión del riesgo de desastres. Santiago: CIGIDEN

Trejo-Rangel, M.A., Marchezini, V., Rodriguez, D.A. \& da Silva Oliveira, M. (2021). Participatory 3D model to promote intergenerational engagement for disaster risk reduction in São Luiz do Paraitinga, Brazil. Disaster Prevention and Management, 3o(3), 308-326. https://doi.org/10.1108/ DPM-08-2020-0262

Tuhiwai, L. (2016). A descolonizar las metodologías: investigación y pueblos indígenas. Santiago: LOM ediciones.

Valiente, S. (2020). Posicionar la investigación de borde. Revista Latinoamericana de Metodología de las Ciencias Sociales, 10(1),1-12. https://doi.org/10.24215/18537863eo72

Villasante, T.R. (2019). Distinciones, fracasos y transducciones co-oper-activas. En Paño Yáñez, P., Rébola, R. \& Suárez Elías, M. (Comps.), Procesos y Metodologías Participativas: Reflexiones y experiencias para la transformación social (pp. 18-41). Buenos Aires. CLACSO - UDELAR

Villasante, T.R. (2014) Redes de vida desbordantes. Fundamentos para el cambio desde la vida cotidiana. Madrid. La Catarata.

Villasante, T.R. (2011). Estilos y epistemología en las metodologías participativas. En Falck, A., \& Paño, P. (Eds.), Democracia Participativa y Presupuesto Participativos: Acercamiento y Profundización sobre el debate actual (pp. 123-148). Málaga, CEDMA

Villasante, T.R. (2006). Las matrices y los tetralemas: juegos con la complejidad para hacerla más creativa socialmente. En Villasante, T. (Ed.), Desbordes Creativos: Estilos y estrategias para la transformación social (pp. 150-172). Madrid. La Catarata.

Villasante, T.R. (2017). Democracias transformadoras: experiencias emergentes y alternativas desde los comunes. Barcelona: El Viejo Topo.

UN Office for Disaster Risk Reduction. (2015). Sendai framework for disaster risk reduction $2015-2030$. Geneva: UNDRR. 